\title{
In vitro expansion of human beta cells
}

\author{
S. Efrat
}

Received: 25 March 2008 / Accepted: 4 April 2008 / Published online: 29 April 2008

(C) Springer-Verlag 2008

\begin{abstract}
Abbreviation
GFP green fluorescent protein
\end{abstract}

To the Editor: Expansion of beta cells from isolated adult human islets in tissue culture represents an attractive potential source of cells for cell therapy for diabetes. Evidence supports the regeneration of adult mouse beta cells in vivo from both insulin-producing cells $[1,2]$ and pancreatic duct cells [3], and recent analyses of autopsied human pancreatic tissue suggest that human islets may grow by beta cell replication [4]. However, assessment of beta cell proliferation in vitro is much harder, since the beta cell phenotype is rapidly lost $[5,6]$, making it difficult to determine whether the loss of beta cell markers in the expanded cells reflects beta cell dedifferentiation, or beta cell death accompanied by expansion of pancreatic cells from a non-beta cell origin. In genetic lineage-tracing studies using islets from transgenic mice, the specific labelling of beta cells with a fluorescent protein produced under the control of an ubiquitous promoter allowed tracking of mouse beta cell fate in vitro [7]. These studies demonstrated that mouse beta cells dedifferentiated and survived for a few weeks under the particular culture conditions employed; however, no significant beta cell proliferation could be detected. In a recent article in Diabetologia Parnaud et al. [8] compared in vitro proliferation of human and rat beta cells, which were purified from

\section{S. Efrat $(\bowtie)$}

Department of Human Molecular Genetics and Biochemistry,

Sackler School of Medicine, Tel Aviv University,

Ramat Aviv,

Tel Aviv 69978, Israel

e-mail: sefrat@post.tau.ac.il isolated islets by labelling with Newport Green. This study documented a marked difference in proliferation between the two groups of cells, with the purified rat beta cells showing a massive replication capacity and the human beta cells showing no detectable proliferation. The authors concluded that human beta cells could not be expanded in vitro under the culture conditions utilised, which were the same for both cell groups. However, in the absence of a stable beta cell marker, Parnaud et al. could not exclude the possibility that some of the insulin-negative cells which proliferated in their cultures were derived from dedifferentiated beta cells.

Our group has recently developed a lineage-tracing approach based on lentivirus vectors, which allows the fate of cultured human beta cells to be monitored [9]. In contrast to Parnaud et al., using this method we found evidence for massive proliferation of cells derived from beta cells. Beta cells dissociated from isolated human islets were specifically labelled with green fluorescent protein (GFP) produced under the control of the cytomegalovirus promoter. In this system, GFP production was blocked by a loxPflanked DNA fragment. Removal of the block, using Cre recombinase produced under control of insulin gene promoter, activated GFP production only in beta cells. Label-positive, insulin-negative cells derived from beta cells of 15 human donors aged 17-60 years were shown to proliferate for a maximum of 16 population doublings. We did not observe age-related differences in the proliferation capacity of the cells within this age range. The approximate doubling time of dedifferentiated beta cells 
was 7 days, similar to the doubling time of the GFPnegative cells present in the same culture. The similar proliferation rates of beta and non-beta cells in these cultures was demonstrated by the finding that cultures at consecutive passages contained a stable fraction of cells derived from beta cells (about 40\%). Consistent with Parnaud et al. [8], we found that FACS-sorted GFP-positive cells did not replicate well. However, their proliferation rate was restored if the culture medium was supplemented with medium conditioned by non-beta pancreatic cells [9]. It should be noted, however, that Parnaud et al. [8] sorted primary insulin-positive cells, while our sorting purified dedifferentiated beta cells following growth in cell culture, making it difficult to compare the two studies.

Analysis of total mouse islet cells by the virus-tracing method revealed a much lower rate of proliferation of labelled cells, compared with human cells, under similar culture conditions [9], confirming the results obtained with transgenic mouse islets, and suggesting that the culture conditions were better suited for human than mouse beta cell expansion. Thus, a striking species difference emerges from the results of both Parnaud et al. and our own group with respect to beta cell proliferation in vitro: while rat beta cells replicate in the absence of support from other pancreatic cells, human dedifferentiated beta cells seem to require a soluble factor(s) released by non-beta cells, and mouse dedifferentiated beta cells cannot replicate even in the mixed culture. These differences, as well as the nature of the soluble growth factor(s), are of great interest and merit further research.

Why expand dedifferentiated beta cells? We believe that these cells maintain open chromatin structure in chromosomal regions important for beta cell function, and thus represent good candidates for redifferentiation into functional beta cells, given appropriate stimuli. These hypotheses need to be tested in future work.

Duality of interest The author declares that there is no duality of interest associated with this manuscript.

\section{References}

1. Dor Y, Brown J, Martinez OI, Melton DA (2004) Adult pancreatic beta-cells are formed by self-duplication rather than stem-cell differentiation. Nature 429:41-46

2. Nir T, Melton DA, Dor Y (2007) Recovery from diabetes in mice by beta cell regeneration. J Clin Invest 117:2553-2561

3. Xu X, D'Hoker J, Stangé G et al (2008) Beta cells can be generated from endogenous progenitors in injured adult mouse pancreas. Cell 132:197-207

4. Meier JJ, Butler AE, Saisho Y et al (2008) Beta cell replication is the primary mechanism subserving the postnatal expansion of beta cell mass in humans. Diabetes DOI 10.2337/db07-1369

5. Beattie GM, Itkin-Ansari P, Cirulli V et al (1999) Sustained proliferation of PDX $-1^{+}$cells derived from human islets. Diabetes 48:1013-1019

6. Ouziel-Yahalom L, Zalzman M, Anker-Kitai L et al (2006) Expansion and redifferentiation of adult human pancreatic islet cells. Biochem Biophys Res Commun 341:291-298

7. Weinberg N, Ouziel-Yahalom L, Knoller S, Efrat S, Dor Y (2007) Lineage tracing evidence for in vitro dedifferentiation but rare proliferation of mouse pancreatic beta-cells. Diabetes 56: 1299-1304

8. Parnaud G, Bosco D, Berney T et al (2008) Proliferation of sorted human and rat beta cells. Diabetologia 51:91-100

9. Russ HA, Bar Y, Ravassard P, Efrat S (2008) In vitro proliferation of cells derived from adult human beta cells revealed by celllineage tracing. Diabetes DOI 10.2337/db07-1283 